\title{
Collaboration Networks in the Brazilian Scientific Output in Evolutionary Biology: 2000-2012
}

\author{
DIRCE M. SANTIN ${ }^{1}$, SAMILE A.S. VANZ ${ }^{2}$ and IDA R.C. STUMPF ${ }^{2}$ \\ ${ }^{1}$ Universidade Federal do Rio Grande do Sul, Biblioteca do Instituto de Ciências Básicas da Saúde, \\ Rua Sarmento Leite, 500, Centro Histórico, 90050-170 Porto Alegre, RS, Brasil \\ ${ }^{2}$ Universidade Federal do Rio Grande do Sul, Faculdade de Biblioteconomia e Comunicação, \\ Departamento de Ciências da Informação, Programa de Pós-graduação em Comunicação e \\ Informação, Rua Ramiro Barcellos, 2705, Santana, 90035-007 Porto Alegre, RS, Brasil
}

Manuscript received on December 8, 2014; accepted for publication on March 2, 2015

\begin{abstract}
This article analyzes the existing collaboration networks in the Brazilian scientific output in Evolutionary Biology, considering articles published during the period from 2000 to 2012 in journals indexed by Web of Science. The methodology integrates bibliometric techniques and Social Network Analysis resources to describe the growth of Brazilian scientific output and understand the levels, dynamics and structure of collaboration between authors, institutions and countries. The results unveil an enhancement and consolidation of collaborative relationships over time and suggest the existence of key institutions and authors, whose influence on research is expressed by the variety and intensity of the relationships established in the co-authorship of articles. International collaboration, present in more than half of the publications, is highly significant and unusual in Brazilian science. The situation indicates the internationalization of scientific output and the ability of the field to take part in the science produced by the international scientific community.
\end{abstract}

Key words: Co-authorship, Collaboration networks, Evolutionary Biology, Scientific collaboration, Scientific output, Scientometrics.

\section{INTRODUCTION}

Scientific collaboration has increased significantly over the last decades, in different areas and at different levels of aggregation, at a macro (when collaboration occurs and is studied across different countries, continents and areas of knowledge), meso (when it occurs between different institutions, regions or departments in the same university)

Correspondence to: Dirce Maria Santin

E-mail: dirce.santin@ufrgs.br or micro level (between research groups and individuals) (Glänzel 2003). The interest in the collaboration phenomenon has also thrived among researchers and governments all over the world. At the same time that the scientific community is conducting research to understand the structure and dynamics of collaboration, governments are increasingly giving attention to it in order to support the planning of scientific policies.

The analysis of the scientific output resulting from collaboration may expand the understanding 
of the behavior patterns of scientific agent's production (Maltrás Barba 2003). Collaboration indicators reflect the structures of scientific fields by analyzing data on co-authorship and author affiliation. The analysis of networks, in turn, may indicate the players that establish greater connectivity and exert greater influence in certain contexts (Newman 2003).

Bibliometric studies, among which the analysis of collaboration indicators is included, focus on a variety of approaches and dimensions and can be used to evaluate the scientific community, and the scientific output of a country or institution (Meis and Leta 1996). They allow for the evaluation of the scientific development of players, their participation in international scientific cooperation and their contributions to science and economic progress. Furthermore, they can be useful to outline national and institutional strategies, for the planning and evaluation of science policies (Vanz and Stumpf 2010).

This study analyzes collaboration networks present in the Brazilian scientific output in Evolutionary Biology, considering papers published from 2000 to 2012 in journals indexed by Web of Science (WoS). Based on co-authorship data, the study aims to reveal the growth of collaboration during that period, their characteristics and the structure of collaboration between authors, institutions and countries.

Evolutionary Biology is dedicated to the study of changes accumulated by organisms over generations that grant them different physiological and morphological characteristics (National Institutes of Health 2011). Its studies seek to explain the origin and diversification of life, adaptive changes, and extinction of living beings, among others. The field emerged in the nineteenth century, with the studies of Lamarck, Darwin and Mendel, who revolutionized science and led Biological Sciences to a higher level in the global scenario (Salzano 1979). In the mid-twentieth century, the discovery of the DNA structure by Watson and Crick (1953) expanded the possibilities of the field with the establishment of a physical basis for Genetics. The emergence of Molecular Biology in the second half of the twentieth century, integrating knowledge from areas such as Biochemistry and Genetics, has transformed Evolutionary Biology research by granting it new techniques for solving problems, in addition to raising new questions about natural history (Barton et al. 2007).

Currently, Evolutionary Biology is one of the "cornerstones" of science (Barton et al. 2007) and plays a central role in Biological Sciences (Townsend 2010). The structure of the field is complex, gathering both experimental biologists, who work with organism models in laboratory, and naturalists, who observe populations in their natural habitats. Its studies integrate knowledge from disciplines such as Ecology, Biodiversity Conservation, Molecular Biology, Developmental Biology, Genetics, among others. Not only does this configuration strengthen the area in the context of Biological Sciences and basic research in general, but it also expands the possibilities for using new skills in applied areas such as Health Sciences, Human Genetics, Agriculture, and Biodiversity Conservation (Futuyama 2009).

In Brazil, the field has mostly developed since the 1930's and 1950's as a result of its approximation with Genetics (Salzano 1979). Its association with Genetics is still considered extremely relevant in the structure of Brazilian Evolutionary Biology, both with regards to its integration in university departments, such as the Department of Genetics and Evolutionary Biology at the Universidade de São Paulo (USP) ${ }^{1}$, as well as its graduate programs, such as the Graduate Program in Genetics, Conservation and Evolutionary Biology linked to the Instituto Nacional de Pesquisas da

\footnotetext{
${ }^{1}$ Available at: http://dreyfus.ib.usp.br. Access on: Sept 1, 2014
} 
Amazônia (INPA) $)^{2}$. It should be noted, however, that Evolutionary Biology is a different field from Genetics, Molecular Biology and other disciplines, because it has solid theoretical foundations and its own object of research, although part of its studies can be shared by other fields (Barton et al. 2007).

The analysis of collaboration networks in the Brazilian scientific output in Evolutionary Biology is justified by the importance of the field in the national context, by the international impact achieved by publications and by the extremely high rates of international collaboration observed in previous studies (Meneghini and Packer 2006, D'Abadia and Rodrigues 2012, Santin and Silva 2013, Santin et al. 2015). The analysis of collaboration networks in Brazilian co-authored articles on Evolutionary Biology is believed to be able to contribute to the understanding of the structure and the dynamics of output and collaboration in this area and the properties that are inherent to it. The study of the interactions between the main players can also reveal patterns and trends of national and international collaboration in Brazilian science, focusing on the Natural Sciences.

\section{MATERIALS AND METHODS}

The paper consists of a bibliometric study at a macro level of aggregation, focusing on collaboration indicators (Glänzel 2003). Social Network Analysis is used as an important complement to the bibliometric indicators (Vanz and Stumpf 2010), since it enables the understanding of the relationship among players in a graphical representation of the characteristics and dynamics of collaboration.

The main source of data was the Science Citation Index (SCI) on WoS, produced by Thomson Reuters and regarded as one of the most important sources for bibliometric studies. Data were collected in December 2013 using the search

\footnotetext{
${ }^{2}$ Available at: http://gcbev.inpa.gov.br. Access on: Sept 10, 2014.
}

by country strategy $(C U)$, limited to the subject category Evolutionary Biology (WC), the period from 2000 to 2012 (PY), article as document type and limited to SCI. Combined with a strategy of search by topic (TS), using the terms Evolutionary Biology OR Biological Evolution, by country and in the same period of publication, the search resulted in 1,450 articles that make up the corpus of this research.

The records were exported from the database in full format using the Save to Plain Text option, in groups of 500 according to the maximum number allowed for export by WoS, and subsequently placed into a single file. The next procedure was the normalization of the names of authors and institutions listed in the Author (AU) and Address (AD) fields in the bibliographic records, seeking to ensure the reliability of the data analyzed. The software used for data analysis was Microsoft Excel, BibExcel and Gephi. The connections between players were defined using the Force Atlas algorithm, integrated to Gephi, which defines the approximation of the nodes by the strength of their connections and enables groups within the network (clusters) to be identified. The quantification of the articles was of the complete type, assigning an article to each author, institution or country involved (Glänzel 2003).

The methodology consisted of investigating the number of articles and their increase in the period, the levels and dynamics of collaboration, comparing national and international collaboration, and analyzing networks of collaboration between authors, institutions and countries. The study of the increase in scientific production and of collaboration structures was based on the full set of data (20002012). This set was divided into four periods (2000-2003, 2004-2006, 2007-2009, 2010-2012), from which the data were processed separately in the analysis of the collaboration dynamics. Except for the first time window, the others correspond to the triennial evaluation of Brazilian graduate 
programs by the Coordenação de Aperfeiçoamento de Pessoal de Nível Superior (CAPES). Although the first period has an additional year in comparison to the subsequent ones, it gathers a considerably smaller number of articles. It is believed, therefore, that this division seems suited to the research and does not imply prejudice to the observations made sequentially over time.

\section{RESULTS AND DISCUSSION}

The Brazilian scientific output in Evolutionary Biology published from 2000 to 2012 and indexed on the WoS comprises 1,450 articles, which represent approximately $0.5 \%$ of the Brazilian articles published in the period. Figure 1 shows the distribution of articles by year of publication, followed by the annual growth rate. Their growth was observed to be positive in most years, especially 2002, 2004 and 2008. Negative growth rates, noted in 2005, 2006, 2009 and 2011, do not compromise the increase in the number of articles in the period, because the average growth was $15.7 \%$ per year.
This increase, therefore, is higher than the average increase of $10.7 \%$ in the Brazilian scientific output from various fields, as pointed out by Almeida and Guimarães (2013) based on the growth seen in the 1980's, 1990's and 2000's.

The increase in the number of articles published by Brazilian researchers and indexed on the WoS follows the trend towards a greater presence of Brazilian science in the international setting and can be associated with several factors, among which are:

a. the increase and continuity of public investments intended for training human resources for science in Brazil (Guimarães 2004, Leta 2012);

b. the growth of the domestic scientific community, especially in the large field of Biological Sciences, which increased from 1,471 new master' graduates in 2000 to 2,620 in 2010 (CGEE 2012) and from 658 new doctor's graduates in 2000 to 1,238 in 2008 (CGEE 2010);

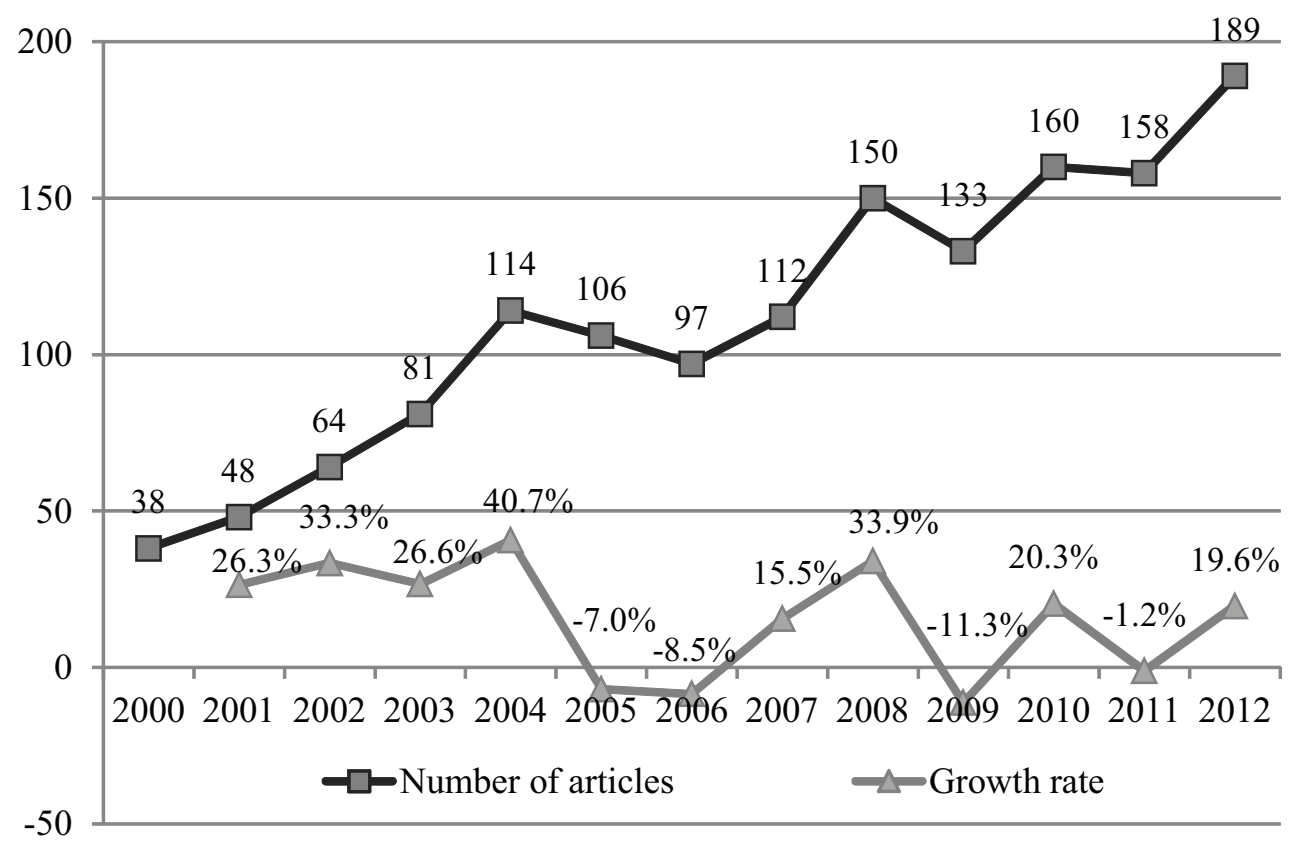

Figure 1 - Brazilian articles on Evolutionary Biology indexed on the WoS and increase in the 2000-2012 period. Source: research data. 
c. the national policy for evaluating researchers and graduate programs based on their merit and scientific productivity (Axt 2004, Leta 2011);

d. the intensification of scientific collaboration at different levels and its potential impact on the productivity of researchers (Persson et al. 2004);

e. the increase in interdisciplinary research on topics related to the origin, diversification and extinction of life, integrating knowledge from diverse disciplines such as Developmental Biology, Molecular Biology, Biodiversity Conservation, Ecology, Genetics, among others (Futuyama 2009); and

f. the current importance of Evolutionary Biology research (Barton et al. 2007) and its central role in Biological Sciences in general (Townsend 2010).

It is important to mention that the increase in the number of Brazilian journals indexed in international databases, which started especially in the second half of the 2000s and is highlighted by authors such as Leta $(2011,2012)$, Vargas and Vanz (2014), among others, does not seem to interfere significantly with the increase in the number of Brazilian Evolutionary Biology articles published in the 2000-2012 period, since only $0.5 \%$ of the articles considered in this research were from Brazilian journals. Therefore, the configuration is shown to be distinct in this field whose articles are published primarily in foreign journals, surpassing even the patterns of Brazilian Biological Sciences, traditionally characterized by their preference to publicize research results in international journals (Meneghini and Fonseca 1990, Melo et al. 2011, Santin et al. 2015).

The evolution of the Brazilian scientific output in Evolutionary Biology was also highlighted by Johnson (2009) in a comparative analysis on the increase in the number of publications in South Africa, Switzerland, New Zealand, China and Brazil in the years 1990-2008. According to the author, Brazilian contributions to global scientific production are substantial and reached around $7 \%$ in 2008 , outpacing the increase seen in the other countries included in the analysis. The contributions from Brazil in this area turn out to be much higher than the percentage achieved by other areas (2.7\% of the world total in 2011) (Cruz 2013) and may be indicative of the thematic specialization that is taking place in Brazilian Evolutionary Biology, which may be associated with the natural advantages of the country in terms of biodiversity, among other factors (Johnson 2009).

\section{LEVELS AND DYNAMICS OF COLLABORATION}

The analysis of article co-authorship reveals the predominance of collaboration, representing a consolidated pattern in Evolutionary Biology. Among the 1,450 articles analyzed, 52 (3.6\%) were published by a single author, while 1,398 (96.4\%) had multiple authors. The proportion of articles with a single author is similar to the value obtained by Vanz and Stumpf (2012) regarding authorship in the Brazilian scientific output published in the years 2004 to 2006 , where the percentage was $3.9 \%$. The average number of authors per article was 5.2, and the median of four authors per article, reinforces a value close to the average. However, the standard deviation of 8.7 indicates discrepancy between the number of authors, given that articles with 135 and 149 authors were found.

The pattern of article co-authorship is consistent with the high level of collaboration in Brazilian Biological Sciences research over the last decades, in which approximately $60 \%$ of researchers have been networked, including relationships that are internal and external to the discipline itself (MenaChalco et al. 2014). The large number of authors identified in some articles indicates the participation of Brazil in the Big Science, which is characterized by complexity and participation of a large number of researchers in studies of global interest (Price 
1976). The Evolutionary Biology interfaces favor the integration of the discipline into the model of major collaborations in Molecular Biology and biomedical research, including, for example, contributions to the Genome Projects.

The general trend towards an increase in scientific collaboration can be seen in Evolutionary Biology through the time window defined for this

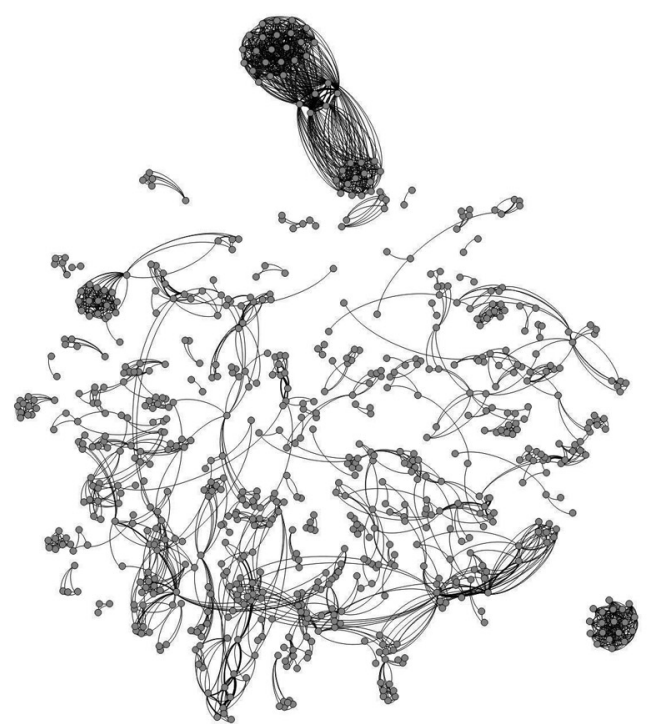

2000-2003: 757 authors and 2,339 connections 231 articles

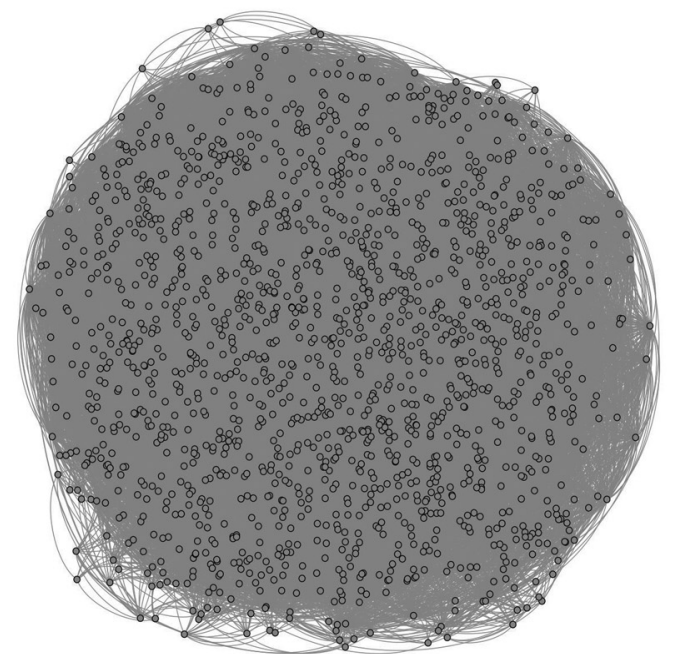

2007-2009: 1,603 authors and 20,157 connections 395 articles study. Figure 2 shows the evolution and dynamics of co-authorship in the Brazilian articles, published in each period. As these are collaborative networks, they are of the undirected type and represent only the authors who had at least one connection in each period.

The first network (2000-2003) is made up of several circles which, although connected by

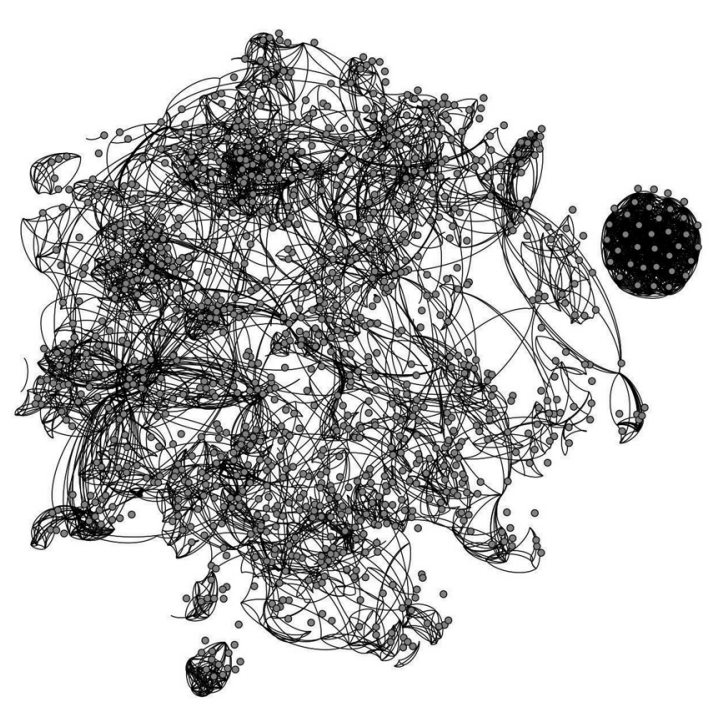

2004-2006: 1,102 authors and 3,390 connections 317 articles

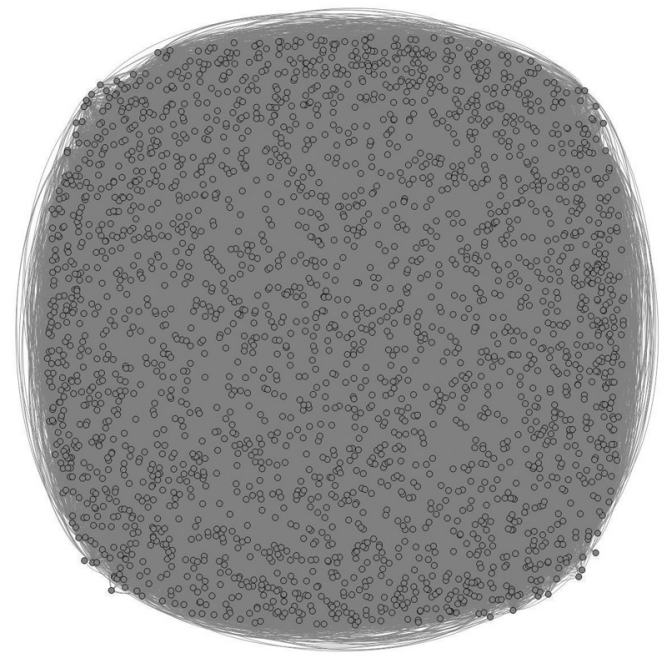

2010-2012: 2,626 authors and 43,963 connections 507 articles

Figure 2 - Evolution of collaboration between authors in the Brazilian scientific output in Evolutionary Biology (2000-2012). Source: research data. 
strong bonds forming small clusters, are kept separated at some points. The average level of the network, represented by the average number of edges (lines) connected to each node (author) is 3.1. Weak ties, represented by nodes with fewer connections or located at the ends, play an important role in the expansion of co-authorship, because they operate connections between parts of the network not directly connected by strong bonds (Barabási 2009). The central players in the network and the cluster leaders, however, establish greater connectivity and exert more influence on the field (Newman 2003). The formation of two clusters that are external to the network and are mostly made up of foreign authors is also observed.

The configuration remains similar in the second period, although there is a trend towards the integration of groups into the large network. Between 2004 and 2006 the connections become more intense and the clusters are larger. Nevertheless, the average level of connections remains stable at 3.1. The groups, which were previously small and isolated, extend their internal and external connections and make the network denser. The stronger nodes take on a prominent place in the clusters and generate greater integration, indicating the formation of so-called "small worlds", where the players in the network are highly interconnected through bonds that establish the co-authorship of publications (Watts 1999).

The third network (2007-2009) represents the phase of highest increase in Brazilian co-authored articles on Evolutionary Biology. The size of the network widens greatly and the average level of connections increases to 12.6 , indicating a high amount of links between authors. At this stage, the increased collaboration is extraordinary and the network is quite complex, requiring closer examination and the identification of key players in order to understand the collaboration phenomenon in the field. This option is adopted in this study to globally analyze the structure in the networks of authors, institutions and countries, presented in more detail in the following sections.

The fourth and final network (2010-2012) reveals the consolidation of collaboration in the field, reaching an average level of 16.7 connections per author. The picture is totally occupied by nodes and connections, and the network reaches its maximum size in this period, revealing the complexity and intensity of collaborative relationships. By adding the numbers of nodes and edges of the four networks, an average collaboration level of 11.5 is achieved. This rate exceeds the average level of 8.0 identified in the co-authorship of publications on Biological Sciences in the years 1990-2010 by Mena-Chalco et al. (2014), with appropriate reservation for the covered period, indicating higher levels of collaboration in the scientific production of Evolutionary Biology when compared with the greater field of Biological Sciences.

Co-authorship relationships represent the socalled "scale-free networks", in which the grouping of authors takes place randomly (Barabási 2009). This characteristic may reveal the potential of a network for absorbing new players and enhancing preexisting collaborative relationships. The results of this research indicate that the expansion of cooperation in Evolutionary Biology is strongly associated with the inclusion of new authors in scientific production (Barabási et al. 2002, Newman 2004), because the increase in the number of nodes associated with each network represented in Figure 2 is high. However, the number of edges increased more than the number of authors observed during the four time window, revealing a significant increase in collaboration between authors, whose relationships become more intense over time.

The dynamics of collaboration shown in Figure 2 confirm that the scientific activity in Brazilian Evolutionary Biology has gradually became more collaborative in the early twenty-first century. This situation follows the trend towards the evolution of collaboration over time in world science as 
verified by Barabási et al. (2002) and Newman (2004), in addition to the increase in collaboration in several Brazilian scientific fields, as pointed out by Mena-Chalco et al. (2014). The enhancement of collaborative relationships also contributes to the formation of densely connected groups of researchers, whose characteristics are observed in greater detail in analyzing the structures of collaboration.

\section{COLLABORATION BETWEEN AUTHORS}

While the analysis of the collaboration dynamics helps the understanding of the evolution of coauthorship over time, the study of the structure of the networks focuses on the perception of the main players and collaboration patterns in the scientific community (Newman 2004). The central positions taken on by the different players (authors, institutions, and countries) and the connections they make with each other at different levels are the object of this research. There is too an attempt to unveil the characteristics of collaboration in Brazilian Evolutionary Biology by using data about the co-authorship of the articles published in the period.

Regarding the collaboration between authors, we chose to analyze the relationships among 30 individuals who authored ten or more articles in the period, and established collaborative relationships with a larger number of authors. Researchers with fewer connections are not represented in the network, although they are considered highly productive in relation to the number of articles published. Figure 3 shows $0.6 \%$ of the 5,182 authors identified in the research corpus in order to facilitate viewing the relationships between the main authors in the field.

The network comprises 30 authors whose representation is based on the intensity of the connections that they established in article coauthorship. The thickness of the lines allows us to identify the players that established greater

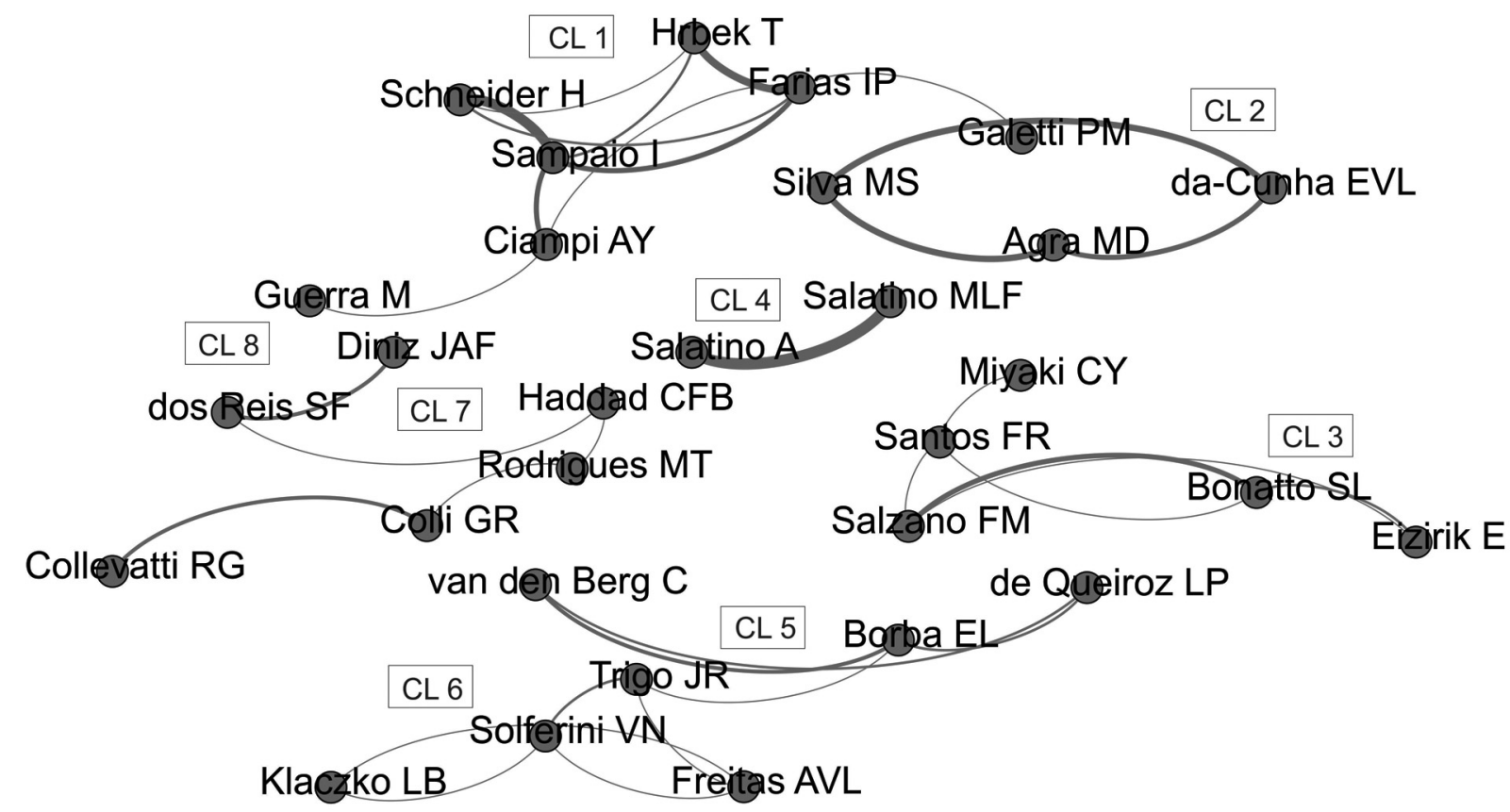

Figure 3 - Collaboration between the most productive and connected authors of Brazilian Evolutionary Biology articles (20002012). Source: research data. 
connectivity and exert greater influence on the network, acting as intermediaries in the information flow and scientific output among their peers (Newman 2004). The proximity between authors reveals small clusters, indicated by the codes CL 1 to CL 8, defined by the authors of this research on the basis of the relationships established in the network. The connections between the clusters are represented by thin lines that represent the "bridges" linking highly connected authors to a group that established relationships with individuals from other groups, favoring the development of the network (Barabási 2009).

The formation of clusters is observed to be strongly influenced by institutional and geographical aspects. The first cluster (CL1) is made up of authors hailing especially from the northern region of the country, affiliated to institutions such as the Universidade Federal do Pará (UFPA) and Universidade Federal do Amazonas (UFAM). The regional approach can also be observed in the second cluster (CL 2), where the authors from the Universidade Federal da Paraíba (UFPB) prevail, in a partnership with the Universidade Federal de São Carlos (UFSCar), represented in the group by one author. The third cluster (CL 3) comprises the authors from the Universidade Federal do Rio Grande do Sul (UFRGS) and the Pontifícia Universidade Católica do Rio Grande do Sul (PUCRS), associated with authors from USP and Universidade Federal de Minas Gerais (UFMG). The group represented by the CL 4 code is formed by two authors only, who are also linked to USP, with intense collaboration in the production of articles. The CL 5 code represents the group comprising researchers from the Universidade Estadual de Feira de Santana (UEFS), Bahia, and the Universidade Federal do ABC, São Paulo. The Universidade Estadual de Campinas (UNICAMP) appears in the CL 6 cluster, including all the authors represented in it. The seventh cluster (CL 7) shows the highest institutional variation, grouping authors from USP,
Universidade Estadual Paulista "Júlio de Mesquita Filho" (UNESP), Universidade Federal de Goiás (UFG), and Universidade de Brasília (UNB). The same occurs with the last cluster (CL 8), which brings together authors from UFG, UNICAMP and Universidade Federal de Pernambuco (UFPE).

Although Figure 3 represents only a stratum in the network of collaboration between authors, it shows the geographic and institutional diversity present in Brazilian Evolutionary Biology research and underscores the importance of researchers from the northern region of the country in studies on topics relating to Genetics and Amazonian Biodiversity (Packer and Meneghini 2006, Meneghini and Packer 2006). This aspect can be seen more clearly in the inter-institutional collaboration network, but it has great importance in the understanding of the collaborative relationships established between researchers. With regard to the institutions to which the authors, present in the network, are affiliated to, the institutions of higher education prevail, such as USP, with five authors; and UNICAMP, with four authors, confirms the importance of institutions like these in the current production of scientific knowledge, widely advocated by authors such as Meadows (1999), Godin and Gingras (2000), among others.

Among the 30 authors represented in the network, 29 are Brazilians and one is a foreigner (Tomas Hrbek), although he has been working in Brazil since 2004 at INPA and UFAM. The most productive researchers in the period were Francisco Mário Salzano (UFRGS); Sandro Luís Bonatto (PUCRS); Antônio Salatino, (USP); Maria Iracilda da Cunha Sampaio (UFPA); and Izeni Pires Farias (UFAM). The authors who were proportionally more connected with regard to the number of articles and co-authors were Izeni Pires Farias (UFAM), Maria Iracilda da Cunha Sampaio (UFPA), Horácio Schneider (UFPA), Tomas Hrbek (UFAM), and Ana Takagaki Yamaguishi (Empresa Brasileira de Pesquisa Agropecuária - Embrapa). 


\section{COLLABORATION BETWEEN INSTITUTIONS}

The institutions to which the authors are affiliated also stand out regarding the network of coauthorship existing among the most productive institutions, which totaled more than 15 articles in the period and established inter-institutional collaboration relationships. This situation strengthens the central role of the main authors and institutions in Brazilian research and indicates the existence of highly productive groups, which engaged in national and international collaboration relationships. The choice of 15 articles as the cutoff point aims to facilitate viewing the relationships within the network. The institutions represented in Figure 4 correspond to $3.3 \%$ of the 1,318 institutions identified in the research corpus.

The network comprises 43 institutions, defined on the map for the intensity of the links established between them. The most intense lines and the central positions of the nodes indicate the institutions that have higher connectivity and exert greater influence on the field (Newman 2003). The centrality of these institutions reveals their importance in relation to the collaboration they established with other institutions in the network. USP, with 424 articles (29.2\%); UNICAMP, with 192 (13.2\%); UFRGS, with 143 (9.9\%); Universidade Federal do Rio de Janeiro (UFRJ), with 116 (8.0\%); and UNESP, with 111 articles (7.6\%), stand out.

The geographical and institutional diversity is highlighted in the network, although the central positions are occupied primarily by institutions of southeastern Brazil, following the leadership patterns achieved by the region in the Brazilian scientific production (FAPESP 2010). This characteristic is very positive and can be linked to the biological diversity found in the different regions of the country and the configurations of the field with regard to aspects such as structure, interdisciplinarity and institutional affiliation of researchers.

Despite the leadership of the universities, a strong presence of national and international research institutes is observed, such as Embrapa in Brazil, with 66 articles (4.5\%), and Centre National de la Recherche Scientifique (CNRS), in France, with 43 articles (2.9\%). This situation demonstrates the complex structure of the area, which brings together universities, research institutes and research centers, among other organizations, integrating both experimental and applied studies (Futuyama 2009). The presence

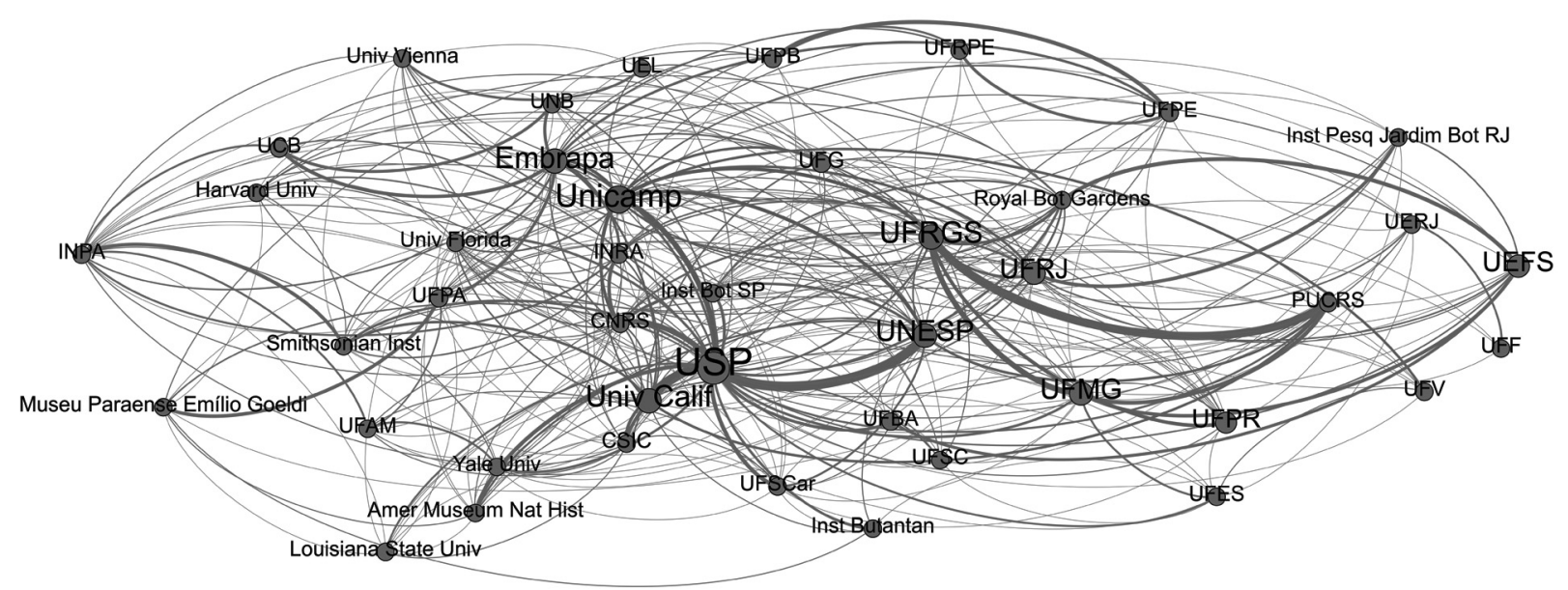

Figure 4 - Collaboration between the most productive institutions regarding the Brazilian scientific output in Evolutionary Biology (2000-2012). Source: research data. 
of foreign institutions in the network follows this trend and indicates the importance of international collaboration in Brazilian Evolutionary Biology.

\section{INTERNATIONAL COLLABORATION}

Collaboration with other countries was found in 753 articles $(51.9 \%)$ and includes 86 partner countries. The rate is high, especially when compared to the rates of international collaboration noted in the Brazilian scientific output from recent years, in which co-authorship with authors from other countries occurred in approximately $30 \%$ of the publications (Leta and Chaimovich 2002, Vanz and Stumpf 2012, Leta et al. 2013). This situation highlights a strong trend towards international collaboration in Brazilian Evolutionary Biology research and unveils a specific characteristic of this field in Brazil. Figure 5 shows the collaboration network with the main partner countries.
The network is formed by Brazil and 29 other countries, selected based on the number of articles and intensity of connections established in coauthoring. The collaborating countries orbit around Brazil, with greater or shorter distance, according to the intensity of the collaboration established with the central node. The most intense lines reinforce the importance of the main partners in the Brazilian scientific production in the field, especially the United States (USA) with 361 articles (24.9\%); United Kingdom, with 161 articles (11.1\%); France, with 85 articles (5.9\%); Germany, with 73 articles (5.0\%); and Argentina, with 72 articles (5.0\%).

The relative centrality taken on by the USA in the network reveals how important the participation of that country in Brazilian Evolutionary Biology research is, and confirms its position as Brazil's main partner in the production of scientific knowledge (Leta and Chaimovich 2002, Glänzel

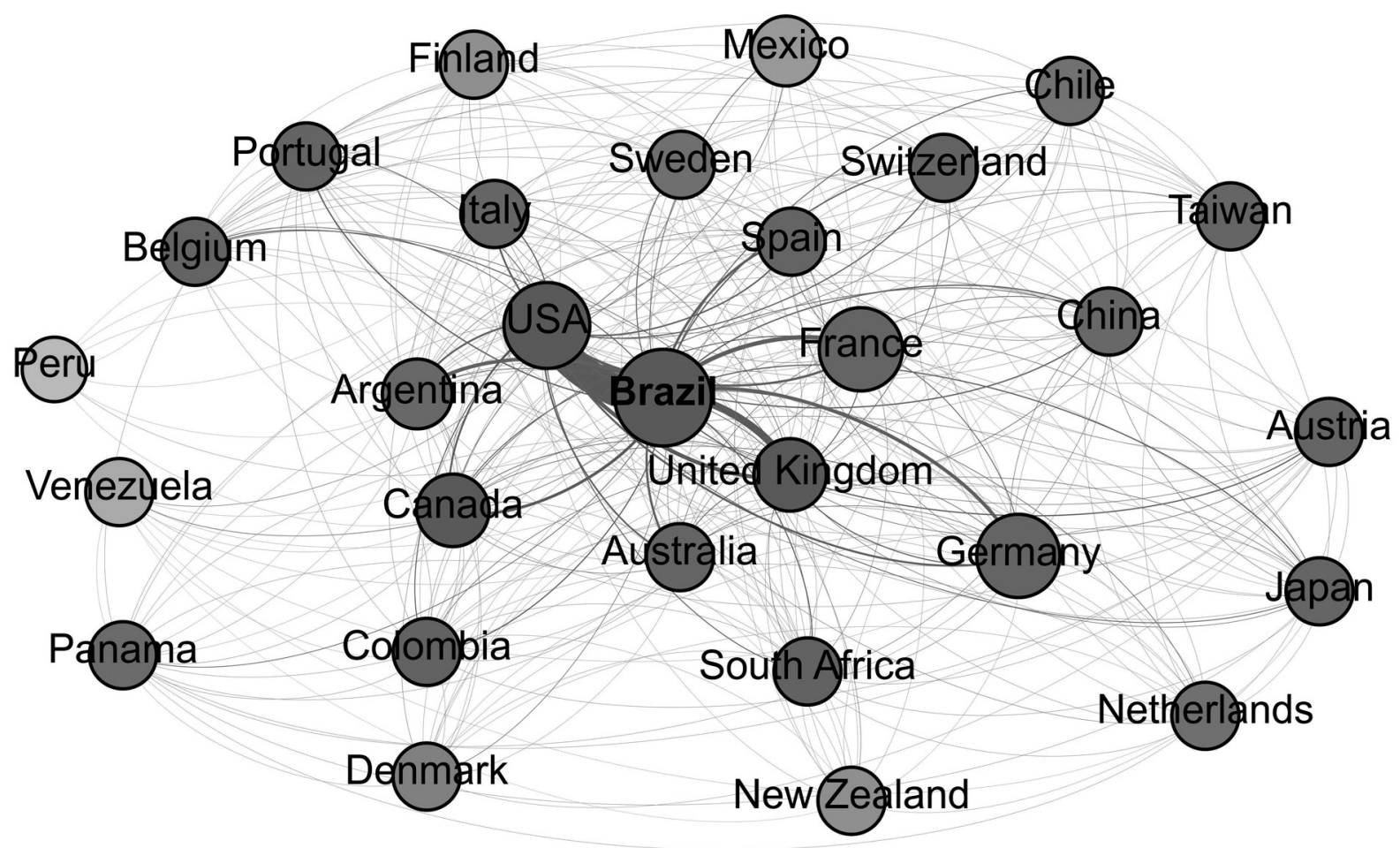

Figure 5 - Collaboration network with main partner countries regarding the Brazilian scientific output in Evolutionary Biology (2000-2012). Source: research data. 
et al. 2006, Packer and Meneghini 2006, Vanz and Stumpf 2012). The strong participation of the USA is also consistent with the leadership exercised by the country in the international scientific community, with emphasis on the Natural Sciences (Mueller and Oliveira 2003).

The presence of European countries follows the existing collaboration trend in Brazilian science (Leta and Chaimovich 2002, Packer and Meneghini 2006) and can be associated to the tradition of Europe in biological evolution studies, especially in nations such as the United Kingdom, Germany and France (Barton et al. 2007). The tradition in research from an evolutionary perspective and the use of advanced and expensive molecular techniques make these countries take precedence over Argentina among the main partners, although this country has been pointed out by several studies as the second main partner of Brazil in the scientific output of different fields (Glänzel et al. 2006, Vanz and Stumpf 2012).

The international collaboration noted in the articles can also have its level of cooperation analyzed for the number of countries involved in co-authoring. Among the items produced through international collaboration, 484 (64.3\%) consisted of bilateral collaboration, 148 (19.6\%) of trilateral collaboration, and 121 (16.1\%) of multilateral collaboration. The predominance of bilateral collaboration follows the trend found by Vanz and Stumpf (2012) in the Brazilian scientific output published in the 2004-2006 period, in which most of the articles resulting from international co-authorship had the participation of Brazil and another country. The last level, which brings together articles produced by authors from four or more countries, included seven articles published by authors from ten to fifteen countries, and eight articles produced in collaboration by sixteen or more countries, including Brazil. The average number of countries per article was 1.9 and the median was 2.0. The mode of the number of countries per work was 1.0, and the standard deviation was 1.8 . The stability of the data proves the regularity of international collaboration in Brazilian Evolutionary Biology and reinforces the existing pattern of collaboration in the field.

\section{CONCLUSIONS}

Scientific collaboration has achieved major importance over the last decades, becoming a strategic issue for planning and evaluating national and institutional scientific policies. Scientific collaboration networks constitute dynamic phenomena that are constantly changing according to the movements of researchers and the connections between them, as well as external factors. The increase in production and the consolidation of collaboration as a scientific practice were highlighted in this study, which underscored two distinct and complementary aspects: the dynamics and the structure of co-authorship relationships in Brazilian articles on Evolutionary Biology published between 2000 and 2012.

The analysis of collaboration dynamics between authors demonstrated the growth of co-authoring relationships in four distinct and sequential periods, allowing the evolvement of the phenomenon over time to be understood. While the period from 2007 to 2009 represents the phase of largest increase in Brazilian co-authored articles on Evolutionary Biology, the period from 2010 to 2012 is marked by the consolidation of collaboration in the area, revealing the complexity of the relationship between researchers. On the other hand, studying the structure of collaboration between authors, institutions and countries enabled us to know the main actors and the relationships they established in the national and international scientific community. The analysis of collaboration networks also indicated the central authors and institutions whose influence on studies is expressed by the variety and intensity of the relationships established in article co-authorship. 
The pattern of international collaboration, found in more than half of the articles is unusual in the Brazilian scientific output and may result in broadening the impact of publications in the global scenario. The collaboration with authors from other countries also indicates the internationalization of scientific output and the capacity of the area to take part in the science produced within the international scientific community. From this perspective, the results of this study point to new possibilities for understanding the phenomenon of major collaborations in Evolutionary Biology, in addition to enabling an analysis of the possible correlation between the high level of international collaboration and the impact achieved by the publications.

\section{RESUMO}

Este artigo analisa as redes de colaboração existentes na produção científica brasileira em Biologia Evolutiva, considerando os artigos publicados no período de 2000 a 2012 em periódicos indexados pela Web of Science. A metodologia integra técnicas bibliométricas e recursos da Análise de Redes Sociais para descrever o crescimento da produção científica e compreender os níveis, as dinâmicas e a estrutura da colaboração entre autores, instituições e países. Os resultados revelam o aumento e a consolidação das relações de colaboração no decorrer do tempo e sugerem a existência de autores e instituições centrais, cuja influência nas pesquisas se expressa pela variedade e intensidade das relações estabelecidas na coautoria dos artigos. A colaboração internacional, presente em mais de metade das publicações, é altamente significativa e incomum na ciência brasileira. A situação indica a internacionalização da produção científica e a capacidade da área de integrar-se à ciência produzida no meio científico internacional.

Palavras-chave: coautoria, redes de colaboração, biologia evolutiva, colaboração científica, produção científica, cientometria.

\section{REFERENCES}

ALMEIDA ECE AND GUIMARÃES JA. 2013. Brazil's growing production of scientific articles: how are we doing with review articles and other qualitative indicators? Scientometrics 97(2): 287-315.

AXT M. 2004. O pesquisador frente à avaliação na pósgraduação: em pauta novos modos de subjetivação. Psicol Soc 16(1): 69-85.

BARABÁSI AL. 2009. Linked (conectado): a nova ciência dos networks. São Paulo: Leopardo.

BARABÁSI AL, JEONG H, NEDA Z, RAVASZ E, SCHUBERT A AND VICSEK T. 2002. Evolution of the social network of scientific collaboration. Phys A 311: 590-614.

BARTON NH, BRIGS DEG, EISEN JA, GOLDSTEIN DB AND PATEL NH. 2007. Evolution. New York: Cold Spring Harbor.

CGEE - CEnTro de GestÃo e Estudos EstratéGicos. 2010. Doutores 2010: estudos da demografia da base técnico-científica brasileira. Brasília: CGEE.

CGEE - CENTRO DE GESTÃo E Estudos EstratéGicos. 2012. Mestres 2012: estudos da demografia da base técnico-científica brasileira. Brasília: CGEE.

CRUZ CHB. 2013. O desafio de aumentar o impacto da ciência brasileira. Available at http://www.fapesp.br/ eventos/2013/05/confap/desafio-impacto-confap.pdf $>$. Accessed on 16 Ago. 2014.

D'ABADIA PL AND Rodrigues FM. 2012. Genética evolutiva: uma análise da produção científica. Estudos 39(3): 345-352.

FAPESP - FUNDAÇÃO DE AMPARO À PESQUISA DO ESTADO DE SÃO PAULO. 2010. Indicadores de ciência, tecnologia e inovação em São Paulo. Available at http://www.fapesp. br/6479. Accessed on 20 Ago. 2014.

FUTUYAMA DJ. 2009. Biologia Evolutiva. $3^{\mathrm{a}}$ ed., Ribeirão Preto: FUNPEC Editora.

GLÄNZEL W. 2003. Bibliometrics as a research field. Course Handouts.

GLÄNZEL W, LETA J AND THIJS B. 2006. Science in Brazil. Part 1: a macro-level comparative study. Scientometrics 67(1): 67-86.

GODIN B AND GINGRAS Y. 2000. The place of universities of the system of knowledge production. Res Policy 29(2): 273-278.

Guimarães JAA. 2004. A pesquisa médica e biomédica no Brasil: comparações com o desempenho científico brasileiro e mundial. Ciênc Saúde Colet 9(2): 303-327.

JOHNSON SD. 2009. Darwin's legacy in South African evolutionary biology. S Afr J Sci 105(11/12): 403-409.

LETA J. 2011. Indicadores de desempenho, ciência brasileira e a cobertura das bases de dados. Rev USP 89: 62-77.

LETA J. 2012. Brazilian growth in the mainstream science: the role of human resources and national journals. J Scientometrics Res 1(1): 44-52.

LETA J AND CHAIMOVICH H. 2002. Recognition and international collaboration. Scientometrics 53(3): 325-335.

LETA J, THIJS B AND GLÄNZEL W. 2013. A macro-level study of science in Brazil: seven years later. Encontros Bibli 18(36): 51-66. 
MALTRÁS BARBA B. 2003. Los indicadores bibliométricos. Gijón: Ediciones Trea.

MEAdows AJ. 1999. A comunicação científica. Brasília: Briquet de Lemos.

MEIS L AND LETA J. 1996. O perfil da ciência brasileira. Rio de Janeiro: Editora da UFRJ.

MELO PLC, MUGNAINI R AND LETA J. 2011. A new indicator for international visibility: exploring Brazilian scientific community. Scientometrics 88(1): 311-319.

MENA-CHALCO JP ET AL. 2014. Brazilian bibliometric coauthorship networks. J Am Soc Inf Sci Technol 65(7): 1424-1445.

MENEGHINI R AND FONSECA L. 1990. Índices alternativos de avaliação da produção científica em Bioquímica no Brasil. Ciênc Cult 42(9): 629-645.

MENEGHINI R AND PACKER AL. 2006. Articles with authors affiliated to Brazilian institutions published from 1994 to 2003 with 100 or more citations: II - Identification of thematic nuclei of excellence in Brazilian Science. An Acad Cienc 78(4): 855-883.

MUEller SPM AND OliveIRA HV. 2003. Autonomia e dependência na produção da ciência: uma base conceitual para estudar relações na comunicação científica. Perspect Ciênc Inf 8(1): 58-65.

NATIONAL INSTITUTES OF HEALTH. 2011. National Library of Medicine. Medical Subject Headings. 2011. Available at http://www.ncbi.nlm.nih.gov/mesh. Accessed on 02 Ago 2014.

NEWMAN MEJ. 2003. The structure and function of complex networks. Siam Rev 45(2): 167-256.

NEWMAN MEJ. 2004. Coauthorship networks and patterns of scientific collaboration. Proc Natl Acad Sci USA 101(s1): 5200-5205.

PACKER AL AND MENEGHINI R. 2006. Articles with authors affiliated to Brazilian institutions published from 1994 to 2003 with 100 or more citations: I - The weight of international collaboration and the role of the networks. An Acad Cienc 78(4): 841-853.

PERSSON O, GLÄNZEL W AND DANELL R. 2004. Inflationary bibliometric values: the role of scientific collaboration and the need for relative indicators in evaluative studies. Scientometrics 60(3): 421-432.

PRICE JDS. 1976. O desenvolvimento da ciência: análise histórica, filosófica, sociológica e econômica. Rio de Janeiro: Livros Técnicos e Científicos.

SALZANO FM. 1979. Estudo sobre a Evolução Biológica no Brasil. In: FERRI MG and MOTOYAMA S (Org), História das ciências no Brasil. São Paulo: EdUSP. 241-264.

SANTIN DM AND SILVA RCP. 2013. Internacionalização da produção científica brasileira em Biologia Evolutiva: 2000-2012. In: ENCONTRO NACIONAL DE PESQUISA EM CIÊNCIA DA INFORMAÇÃO - ENANCIB. Florianópolis, 14, Anais... Florianópolis: ANCIB.

SANTIN DM, VANZ SAS AND STUMPF J. 2015. Internacionalização da produção científica em Ciências Biológicas da UFRGS: 2000-2011. Transinformação 27(3): 209-218.

TOWNSEND CR. 2010. Fundamentos em ecologia. $3^{\mathrm{a}}$ ed., Porto Alegre: Artmed.

VANZ SAS AND STUMPF IRC. 2010. Colaboração científica: revisão teórico-conceitual. Perspect Ciênc Inf 15(2): 42-55.

VANZ SAS AND STUMPF IRC. 2012. Scientific output indicators and scientific collaboration network mapping in Brazil. Collnet Journal of Scientometrics and Information Management 6(2): 1-20.

VARGAS RA AND VANZ SAS. 2014. A produção científica do Rio Grande do Sul em Ciências Agrárias representada na base Web of Science. Ciênc Rural 44(5): 950-956.

WATSON JD AND CRICK FHC. 1953. Molecular structure of nucleic acids. Nature 171(4353): 737-738.

WATTS DJ. 1999. Networks, dynamics, and the small-world phenomenon. Am J Sociol 105(2): 493-527. 